\title{
Is Postpartum Uterine Involution Impacted by Instrumental or Operative Procedures? Ultrasound Study
}

\author{
Virginija Paliulyte ${ }^{1,2 *}$, Grazina Stanislava Drasutiene ${ }^{1,2}$, Diana Ramasauskaite1,2, \\ Daiva Bartkeviciene ${ }^{1,2}$, Jolita Zakareviciene ${ }^{1,2}$, Juozas Kurmanavicius ${ }^{3}$ \\ ${ }^{1}$ Clinic of Obstetrics and Gynecology of Vilnius University, Vilnius, Lithuania \\ ${ }^{2}$ Centre of Obstetrics and Gynecology, Vilnius University Hospital Santaros Klinikos, Vilnius, Lithuania \\ ${ }^{3}$ Department of Obstetrics, University Hospital Zurich, Zurich, Switzerland \\ Email: *vpaliulyte@yahoo.com
}

How to cite this paper: Paliulyte, V., Drasutiene, G.S., Ramasauskaite, D., Bartkeviciene, D., Zakareviciene, J. and Kurmanavicius, J. (2018) Is Postpartum Uterine Involution Impacted by Instrumental or Operative Procedures? Ultrasound Study. Open Journal of Obstetrics and Gynecology, 8, 1289-1304.

https://doi.org/10.4236/ojog.2018.813131

Received: August 22, 2018

Accepted: November 2, 2018

Published: November 5, 2018

Copyright (c) 2018 by authors and Scientific Research Publishing Inc. This work is licensed under the Creative Commons Attribution International License (CC BY 4.0).

http://creativecommons.org/licenses/by/4.0/

\begin{abstract}
Objectives: Practitioners are continuously concerned with the differences between the normal puerperium and the uterine involution after operated deliveries. This prospective observational study pays attention to the uterine involution period after the instrumental or operative delivery and compares the results with those observed in uncomplicated labour. Methods: Over two postpartum months 66 women after normal (48) and complicated (18) labour were examined for repeated uterine parameters. The analysis was performed using SPSS version 21 . Results: There was no statistically significant difference between the median uterine size parameters or the uterine artery indices after the normal delivery and instrumental/operative uterine manipulations during the involution period, except for a faster declining trend observed in anteroposterior diameter within the first month after normal labour. The diastolic notch was more frequent in early puerperium after complicated labor, but less frequent later. The diastolic notch did not appear in all the postpartum women even two months after labour. There was evidence of more frequent gas detected in the pathological rather than in the physiological group. Conclusion: Postpartum uterine involution is not impacted by instrumental or operative procedures. After complicated labour gas appearance is more common, but it does not necessarily indicate the presence of endometritis or retained placental tissues.
\end{abstract}

\section{Keywords}

Postpartum Ultrasound, Uterus, Physiology, Pathology, Cesarean Scar 


\section{Introduction}

Considerable scholarly attention has been drawn to the involution of the uterus in recent years. Available data suggest that more evidence could be found on the normal puerperium [1]-[8]. Other studies investigate the pathology of postpartum uterus: the determination of retained placental tissues (RPT), abnormalities of the uterus [9] [10], the impaired involution of the uterine artery flow [11] [12] [13]. Practitioners are continuously concerned with the differences between the normal puerperium and the uterine involution after complicated deliveries: operative evacuation of RPT, caesarean delivery or postpartum endometritis. The reports on these conditions are still sparse and scans are relatively old and poor quality [14] [15] [16].

Puerperal complications are most likely to be related to puerperal infection. In all, $10.7 \%$ of pregnancy-related deaths are caused by infection, the fifth leading cause of fatal puerperal outcomes. Compared with cesarean delivery $(1.7 \%$ $11 \%)$, endometritis after vaginal delivery is relatively infrequent (1\% - 2\%) [17]. Manual removal of the placenta increases the puerperal endometritis rate threefold. The lack of data hinders the prediction of endometritis after complicated labour or the assessment of the healing of the uterine incision after caesarean section (C/S) [17] [18] [19] [20]. There is also a small body of work describing the uterine ultrasound differences found in patients after normal or complicated labour from the earliest puerperium (within two hours after labour) until 8 weeks of postpartum period with original sonograms. Only a few studies include continuous Doppler measurements of uterine arteries during the uterine involution period, or the scope of the examination is very narrow [1] [11] [12] [13].

The aim of this study is to compare the metrical quantitative and qualitative characteristics of the uterus in the puerperium period in women after normal vaginal deliveries (according our previous study) with those observed after pathological labour [21]. The second purpose is to draw attention to the uterus after pathological labour and to find useful guidelines facilitating the monitoring of these patients during the involution period.

\section{Materials and Methods}

A total of 66 participants were invited to participate in this study in delivery rooms, at their active stage of the first period of a singleton term (37 - 42 weeks of gestation) delivery. The inclusion criteria were as follows: term pregnancy, older than 18 years of age, conscious women without any mental disorders or congenital diseases. The exclusion criteria were as follows: preterm or multiple pregnancy, stillbirth, severe postpartum bleeding (intensive care measures were used, B-Lynch suture after labour, uterine devascularisation), congenital uterine disorders, uterine fibroids or oncological diseases. The grouping was done based on the events in the study period. The women after uncomplicated delivery and puerperium comprised the physiological group while the pathological group consisted of patients with the uterine scar after previous or a current $\mathrm{C} / \mathrm{S}$, also 
those after surgical evacuation because of retained placental tissues (RPT) immediately following delivery or those with postpartum endometritis diagnosed within 48 postpartum hours. There were 48 women in the physiological group and 18 women in the pathological group. Each woman was examined 6 times and a serial ultrasonographic examination was carried out on the $1^{\text {st }}, 3^{\text {rd }}, 10^{\text {th }}$, $30^{\text {th }}, 42^{\text {nd }}, 60^{\text {th }}$ days of the postpartum period. The first examination was performed within two hours after vaginal or cesarean delivery. An abdominal ultrasound scan was carried out on the $1^{\text {st }}, 3^{\text {rd }}$ and $10^{\text {th }}$ days, while transvaginal sonoscopy-on the $30^{\text {th }}, 42^{\text {nd }}$ and $60^{\text {th }}$ days. All participants were breastfeeding from the beginning till the end of our study. GE Healthcare Voluson S6 and Voluson S8 systems were used to evaluate gray-scale, Colour Pulse Doppler ultrasound measurements. Uterine measurements were performed on the basis of commonly used recommendations for pelvic ultrasound and Doppler scans [22] [23] [24]. All the participants were provided with the oral and written information about the study, and all participants gave written informed consent before the study began. The study was approved by the Regional Bioethics Committee of the Faculty of Medicine of Vilnius University on the $13^{\text {th }}$ of April 2013 (No.158200-13-605-183).

The uterine size measurements were performed in the longitudinal scan, the coronal scan and the transverse scan [1]. The uterine length $(\mathrm{mm})$ and the anteroposterior diameter (AP) $(\mathrm{mm})$ were measured in longitudinal sections. The AP diameter was measured in the widest part of the longitudinal section perpendicular to the longitudinal uterine axis. The uterine width $(\mathrm{mm})$ was measured in the transverse section, the coronal view was evaluated on the $1^{\text {st }}$ day to exclude the congenital malformations of the uterus.

The endometrial stripe thickness $(\mathrm{mm})$ was measured at its widest point in the longitudinal section and the endometrial contents were evaluated: hyperechoic, hypoechoic or mixed contents were assessed. The uterine angle (degree) was measured in relationship with the longitudinal axis of the body.

In the pathological group with the uterine scar, the uterine scar changes during puerperium were also observed: visualisation, localisation, the length (thickness) $(\mathrm{mm})$ and the width $(\mathrm{mm})$ of the scar in the longitudinal axis of the uterus.

The Color \& Doppler measurements of the uterine artery (to detect Resistance Index (RI) and Pulsatility Index (PI)) were performed at the point where this artery crosses the external iliac artery (beam/flow angles were kept at $30^{\circ}$ ) [1]. RI and PI are vascular parameters of uterine involution. The mean values of both left and right arteries were used. The presence or absence of an early bilateral protodiastolic notch was recorded, defined as a persistent decrease in the blood flow velocity in an early diastole below the diastolic peak velocity.

We also tried to find a correlation between mother's age, BMI, anemia, B group streptococcus infection, smoking, duration of labour and the mean period of membrane rupture, infant birth weight, meconium-stained amniotic fluid, placental site (anterior or posterior uterine wall) and uterine involution parame- 
ters after normal and complicated labour.

The analysis was performed using SPSS, version 21. Continuous variables were summarised using descriptive statistics, including the number of subjects, mean, standard deviation, median, confidence intervals with minimum and maximum values. Kruskal-Wallis test was used to evaluate the associations between the physiological/pathological groups of women and the uterine parameters expressed as continuous variables. Categorical variables were expressed as numbers and percentages. Chi-square test was used to examine the relationships between the physiological/pathological groups of women and other categorical variables. A $\mathrm{p}<0.05$ was regarded as statistically significant.

\section{Results}

A total of 66 women after delivery were examined from 2013 through 2016 (the mean characteristics of these women are presented in Table 1): 48 underwent uncomplicated vaginal delivery and none of them suffered from any complications (fever or hemorrhage) during puerperium; 18 women were diagnosed with obstetrical pathology (2 patients with the uterine scar after previous $\mathrm{C} / \mathrm{S}$ ), 7 -after a current caesarean delivery, 6 with RPT which had to be removed manually ( 3 patients) and instrumentally ( 3 patients), 3 women suffered from postpartum endometritis (clinically and laboratory-confirmed).

A downward trend was observed in all the uterine size parameters in both groups during the involution period (Figure 1 ) and no striking differences between these two groups were revealed $(\mathrm{p}>0.05)$.

Statistically significant changes were observed in the AP measurements carried out from the first day through a month after delivery (Table 2).

The measurements of the anterior and posterior uterine walls showed the same trend in both groups. No differences were detected in the anterior wall measurements, however the posterior uterine wall remained smaller at the end of puerperium in the pathological group $(\mathrm{p}=0.030)$.

The uterine angle deviation, in relationship with the longitudinal axis of the body, in both groups, showed changes ranging from very retroverted to a more

Table 1. Characteristics of women (mean values \pm standard deviation; $p$ ).

\begin{tabular}{cccc}
\hline & $\begin{array}{c}\text { Physiological group } \\
(\mathrm{N}=\mathbf{4 8})(\mathrm{M} \pm \mathrm{SD})\end{array}$ & $\begin{array}{c}\text { Pathological group } \\
\left(\mathrm{N}=1 \mathbf{8}^{* *}\right)(\mathrm{M} \pm \mathrm{SD})\end{array}$ & $\mathrm{p}$ \\
\hline Mean age (year) & $30.33 \pm 3.82$ & $30.33 \pm 5.28$ & 0.995 \\
Mean body mass index (BMI) & $21.72 \pm 3.06$ & $21.11 \pm 3.66$ & 0.503 \\
$\begin{array}{c}\text { Mean duration of labour (hours) } \\
\text { Mean period of membrane rupture } \\
\text { (hours) }\end{array}$ & $7.55 \pm 2.92$ & $9.42 \pm 5.07$ & 0.071 \\
$\begin{array}{c}\text { Mean infant birth weight (grams) } \\
\text { M }\end{array}$ & $3635.98 \pm 409.86$ & $3723.06 \pm 320.85$ & 0.422 \\
\hline
\end{tabular}

${ }^{\star} 24$ primiparous and 24 multiparous in this group of women; ${ }^{*} 10$ primiparous and 8 multiparous in this group of women. 


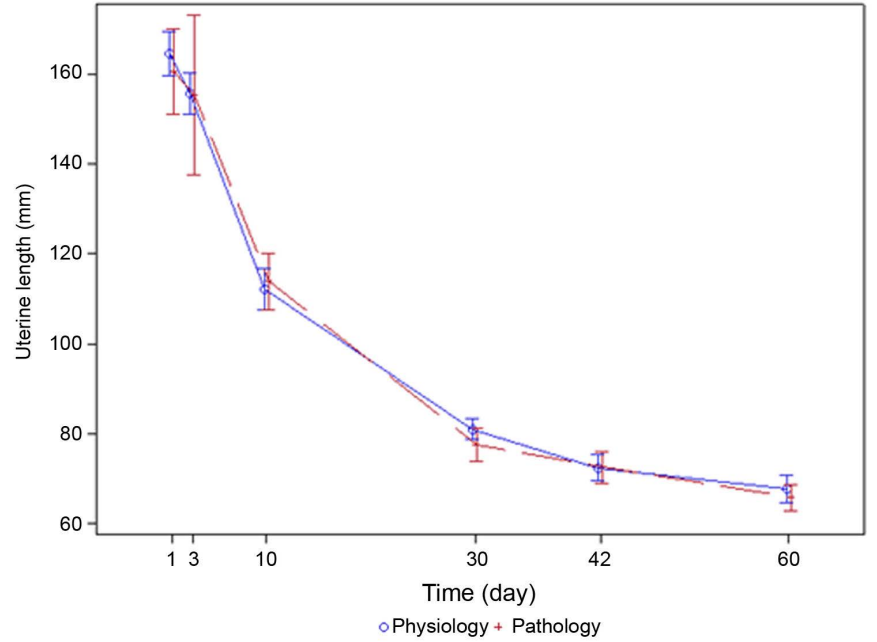

(a)

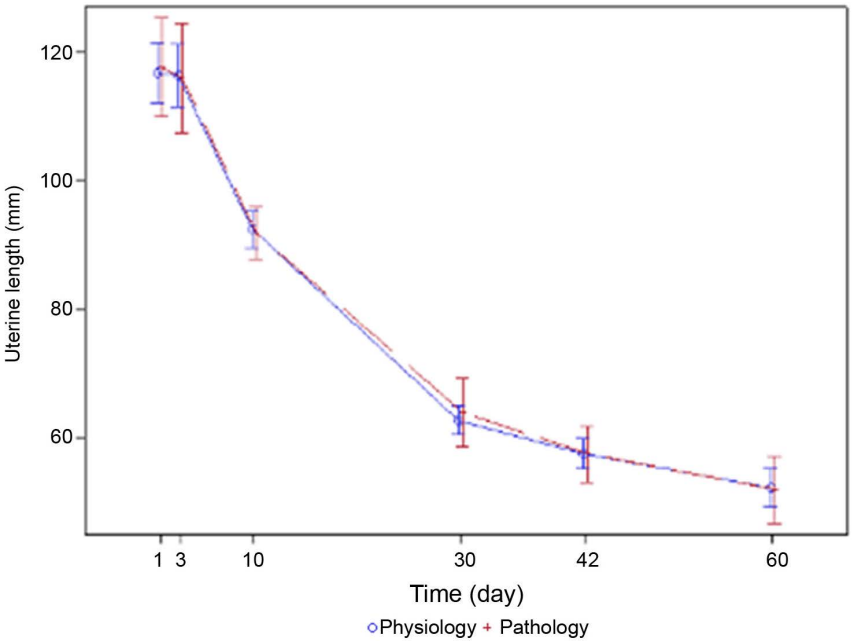

(b)

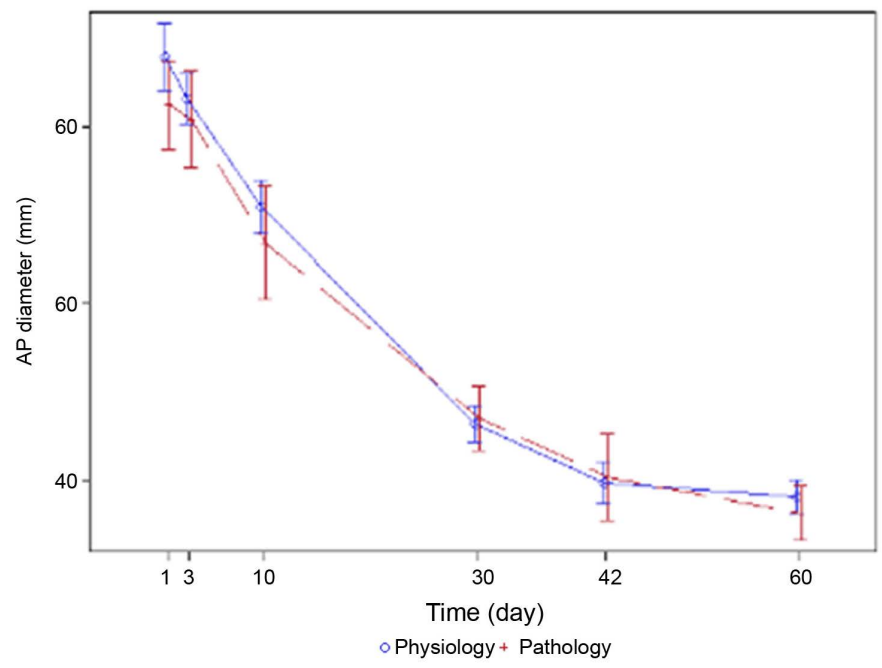

(c)

Figure 1. Uterine length (a), width (b) and AP diameter $(\mathrm{c})(\mathrm{mm})$ regression in the physiological and pathological groups $(\mathrm{p}>0.05)$. 
Table 2. AP diameter regression and changes from the first day until two months after labour in the physiological and pathological groups.

\begin{tabular}{|c|c|c|c|c|c|c|}
\hline \multirow[b]{2}{*}{ Groups; $p$ value } & \multicolumn{6}{|c|}{ AP diameter $[\mathrm{mm}](\mathrm{M} \pm \mathrm{SD})$} \\
\hline & Day 1 & Day 3 & Day 10 & Day 30 & Day 42 & Day 60 \\
\hline $\begin{array}{l}\text { Physiological } \\
\qquad(\mathrm{N}=48)\end{array}$ & $89.50 \pm 12.4$ & $83.00 \pm 9.59$ & $71.00 \pm 10.07$ & $46.00 \pm 6.47$ & $39.00 \pm 7.90$ & $37.00 \pm 6.41$ \\
\hline $\begin{array}{l}\text { Pathological } \\
\quad(\mathrm{N}=18)\end{array}$ & $82.00 \pm 9.46$ & $82.00 \pm 9.92$ & $69.00 \pm 10.33$ & $47.50 \pm 6.22$ & $39.00 \pm 8.87$ & $37.00 \pm 5.58$ \\
\hline $\mathrm{p}$ & 0.128 & 0.466 & 0.239 & 0.690 & 0.918 & 0.373 \\
\hline $\begin{array}{l}\mathrm{p} \text { (changes from } \\
\text { the first day) }\end{array}$ & & 0.261 & 0.284 & 0.023 & 0.072 & 0.168 \\
\hline
\end{tabular}

anteverted position (Figure 2). The significantly more retroverted uterus was found in the pathological group just within two hours after labour: the uterine angle was $-72.50^{\circ} \pm 15.77^{\circ}$ in this group and $-61.50^{\circ} \pm 15.06^{\circ}$ after normal delivery $(\mathrm{p}=0.039)$. Later the same uterine deviation trend was observed during the entire involution period.

Special attention was given to the uterine cavity observation. The endometrial cavity was significantly wider just on the $42^{\text {nd }}$ day after complicated labour ( $\mathrm{p}=$ 0.033), whereas other monitoring days showed no difference (Table 3 ).

The contents of the endometrial cavity were very different in both groups (Figure 3), however, hypoechoic (fluid) contents were likely to be more frequently seen in the middle of the involution period in the pathological group.

Within two hours after the manual or instrumental evacuation of RPT, hyperechoic foci (gas) (Figure 4(a)) or mixed (Figure 4(b)) endometrial stripe can be seen. This view is also observed after the manual evacuation of the placenta.

After the manual or instrumental evacuation, some hyperechoic contents were still seen on day 3 (Figure 5(a), Figure 5(b)), but on day 10, the cavity view was without hyperechoic foci (Figure 5(c), Figure 5(d)).

Gas was detected in $5(10 \%)$ of all the cases of the physiological group (Figure 6(a)) and in 7 (39\%) cases of the pathological group (Figure 6(b), Figure 6(c)). In all the 5 physiological group's cases, gas presented in the isthmic part of the uterus only within 2 hours after labour and later disappeared. On the $1^{\text {st }}$ day, the pathological group included 4 cases after $\mathrm{C} / \mathrm{S}$ and 3 cases after the evacuation of RPT. On the third day, this group had only 3 cases with gas presentation which later disappeared. All the gas inserts present in the pathological group of subjects were found inside the uterine cavity. No gas was present in our observed women with endometritis.

The uterine artery flow examination and indices (RI and PI) measurements showed no significant differences between both groups. In both groups the resistance $(R I)$ of the uterine artery was low immediately after childbirth and steadily increased till the end of the uterine involution (Figure $7(a)$ ). The same 
Table 3. Uterine cavity width changes from the first day until two months after labor in the physiological and pathological groups.

\begin{tabular}{ccccccc}
\hline & \multicolumn{5}{c}{ Uterine cavity width [mm] $(\mathrm{M} \pm \mathrm{SD})$} \\
\hline Groups; $\mathbf{p}$ & Day 1 & Day 3 & Day 10 & Day 30 & Day 42 & Day 60 \\
\hline Physiological (N = 48) & $11.0 \pm 7.6$ & $7.0 \pm 4.2$ & $12.0 \pm 9.2$ & $4.0 \pm 1.7$ & $3.0 \pm 2.4$ & $3.0 \pm 3.6$ \\
Pathological (N = 18) & $11.0 \pm 6.8$ & $9.0 \pm 4.7$ & $11.0 \pm 7.1$ & $5.0 \pm 2.8$ & $5.0 \pm 2.0$ & $3.0 \pm 1.5$ \\
P & 0.663 & 0.324 & 0.369 & 0.103 & 0.033 & 0.696 \\
\hline
\end{tabular}

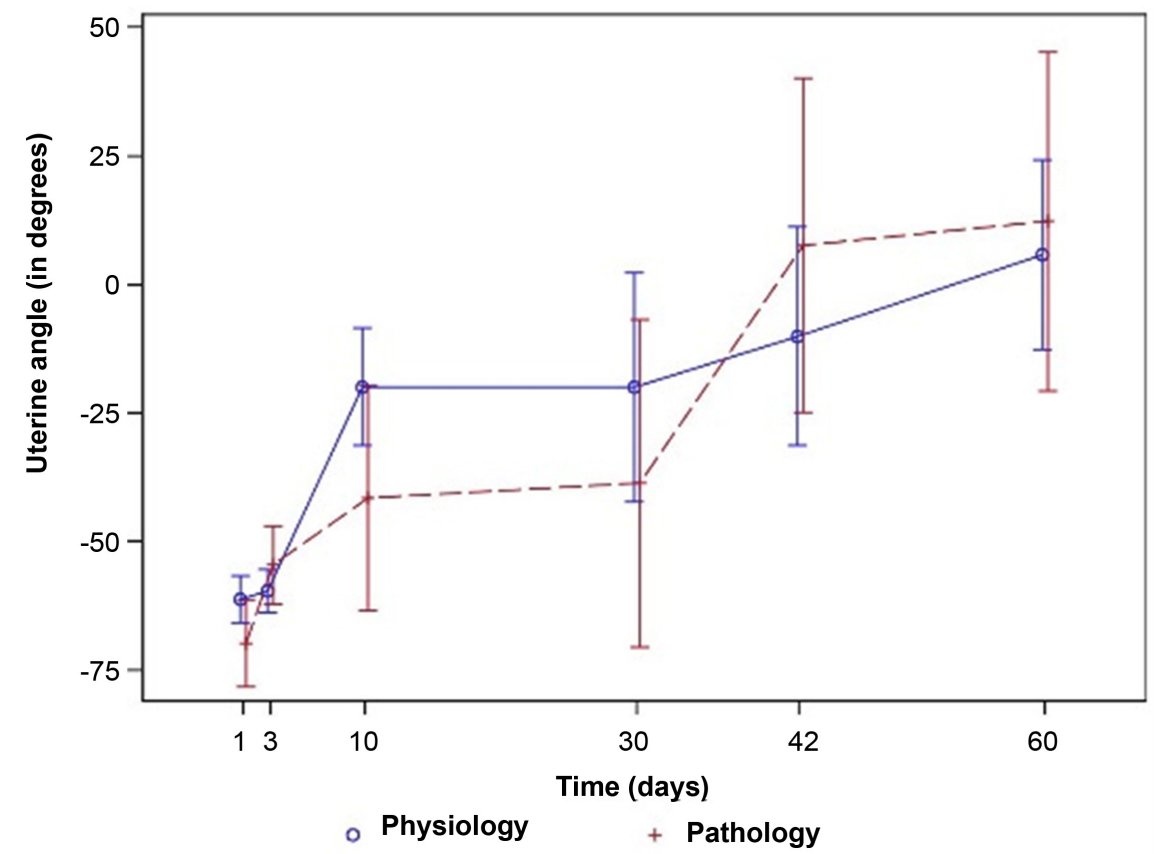

Figure 2. Uterine angle (degrees) deviation in puerperium in the physiological and pathological groups ( $\mathrm{p}=0.039$ on first day; $\mathrm{p}>0.05$ from the $3^{\text {rd }}$ till to $60^{\text {th }}$ postpartum days).

Physiological group: echo-view

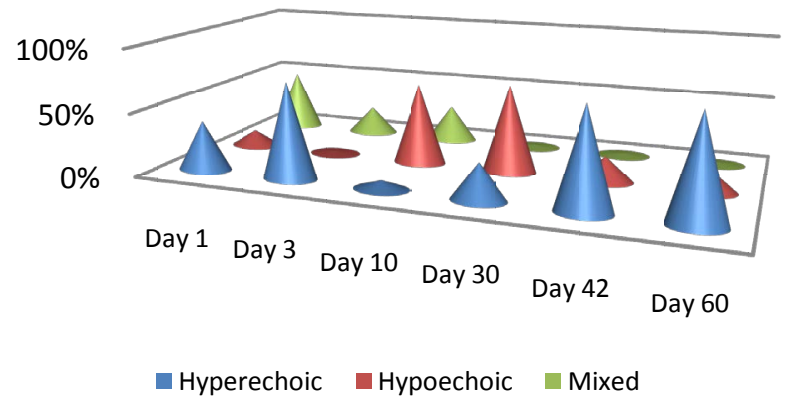

(a)
Pathological group: echo-view

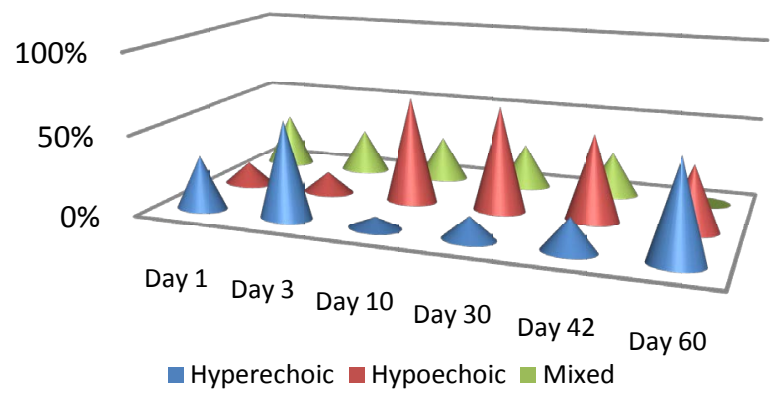

(b)

Figure 3. Uterine cavity view in the physiological (a) and pathological (b) groups.

trend of change was seen in PI where no statistically significant differences were found $(\mathrm{p}>0.05)$ (Figure $7(\mathrm{~b})$ ). 


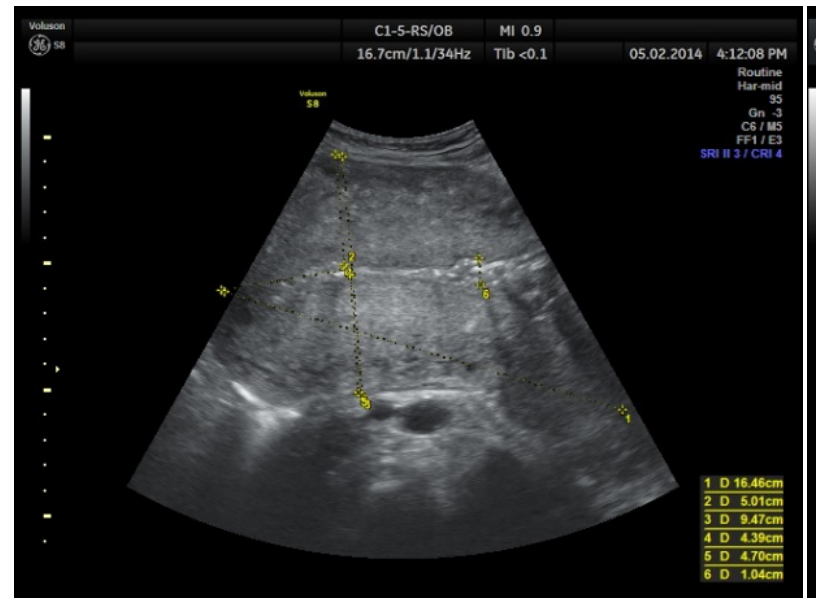

(a)

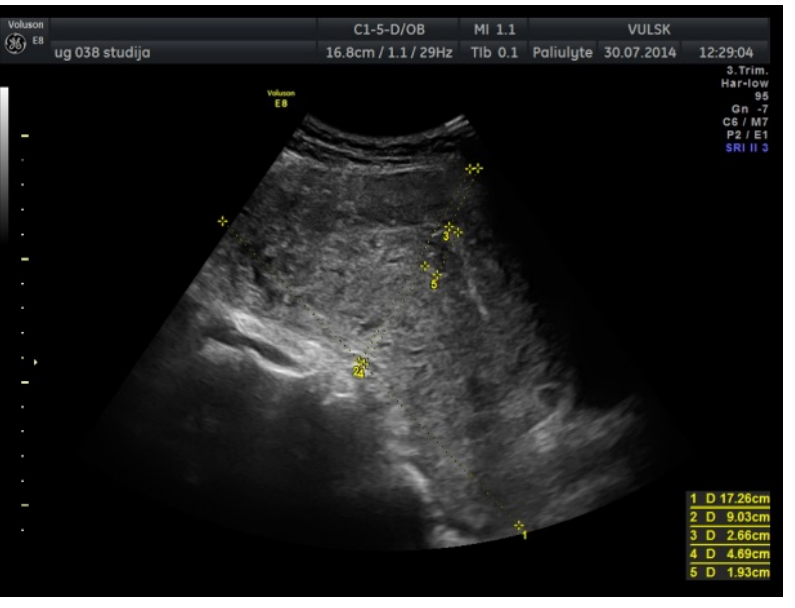

(b)

Figure 4. Uterine cavity (arrow) after RPT removal within two hours after labour: hyperechoic (a) or mixed (b).

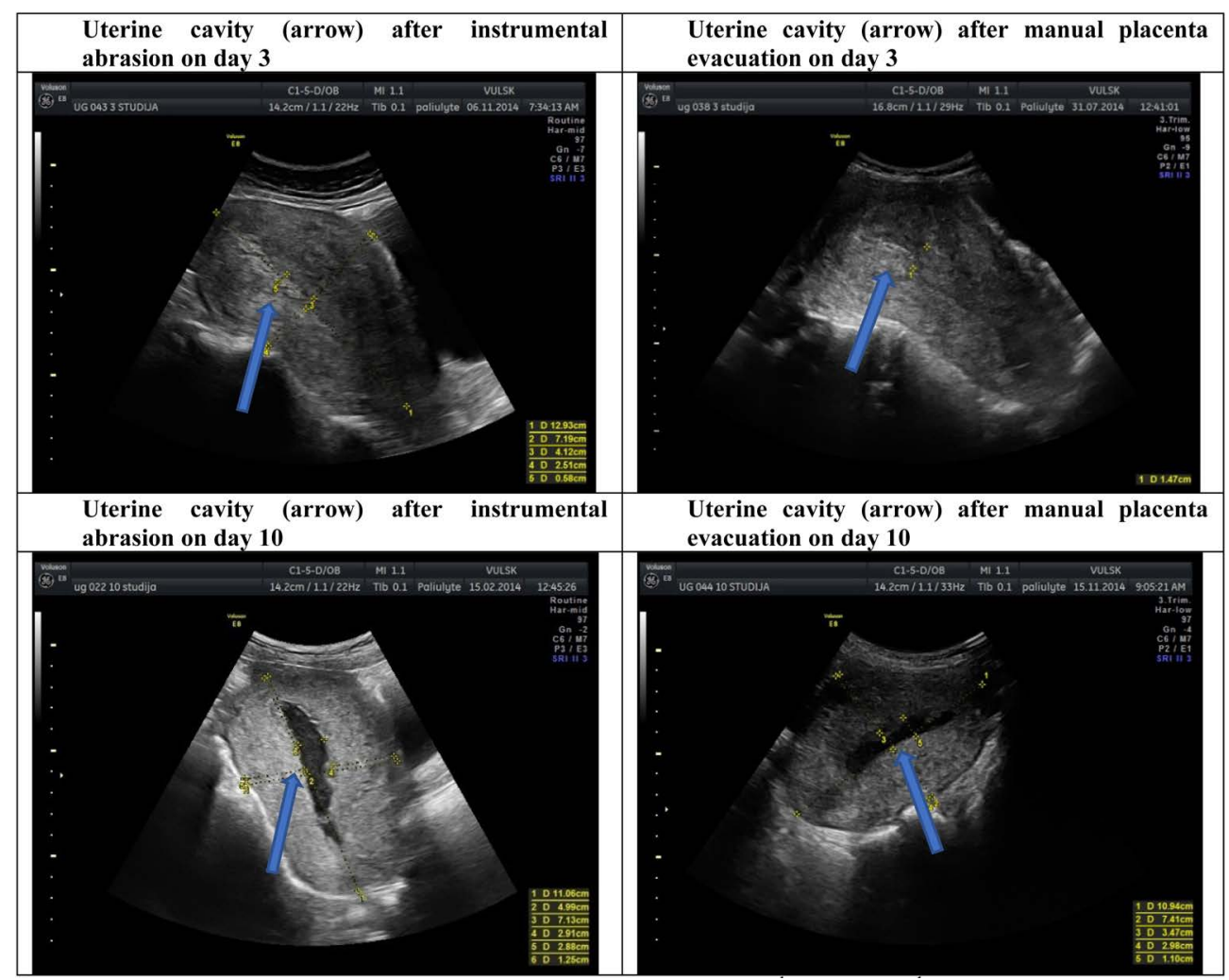

Figure 5. Uterine cavity (arrow) after the RPT removal on $3^{\text {rd }}$ and on $10^{\text {th }}$ postpartum days.

The observation of two groups of women revealed no notching of the uterine artery in the physiological group within two hours after labour (after normal delivery). After the instrumental evacuation of RPT, two cases of notching were diagnosed in the pathological group within two hours after delivery. No notching was detected after a current caesarean delivery, an old scar was not visible in the uterus within the first two hours after labour and no notching at all was detected in the pathological group on the $10^{\text {th }}$ day (Figure 8). In both groups, the 


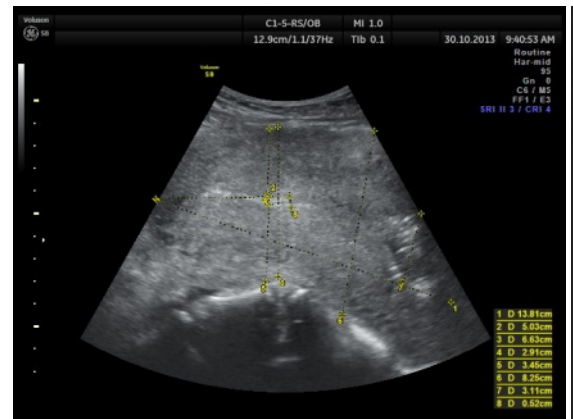

(a)

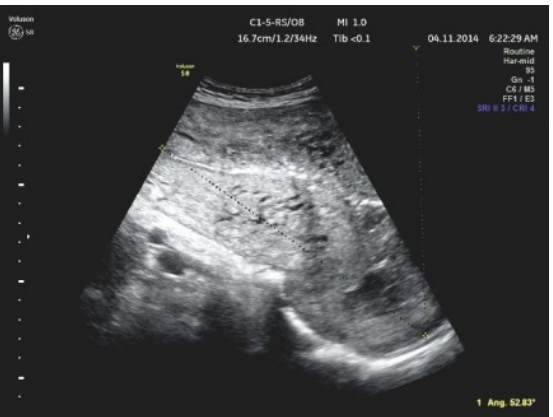

(b)

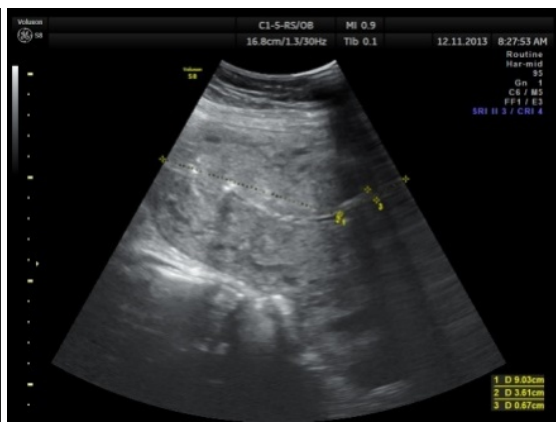

(c)

Figure 6. Gas (arrows-foci of higher echogenicity) after normal labour (isthmic part) (a), after manual placental removal (b) and after $\mathrm{C} / \mathrm{S}$ (c).

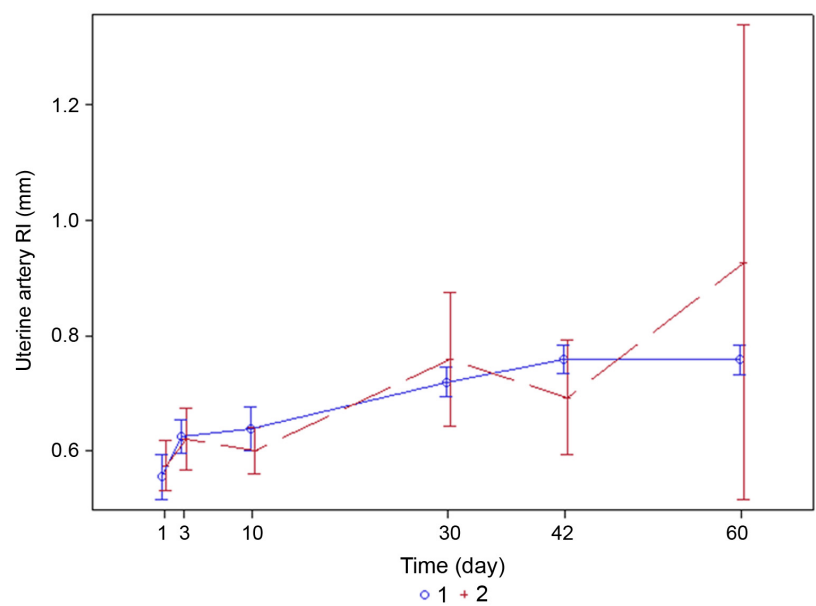

(a)

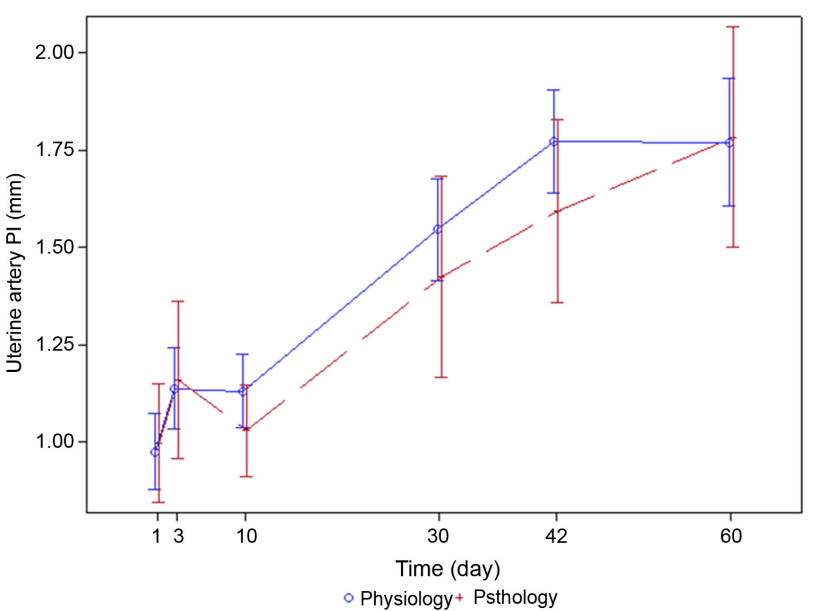

(b)

Figure 7. Changes of RI (a) and PI (b) (uterine artery) after normal (1) and complicated (2) labor (p > 0.05).

\section{Uterine artery notching}

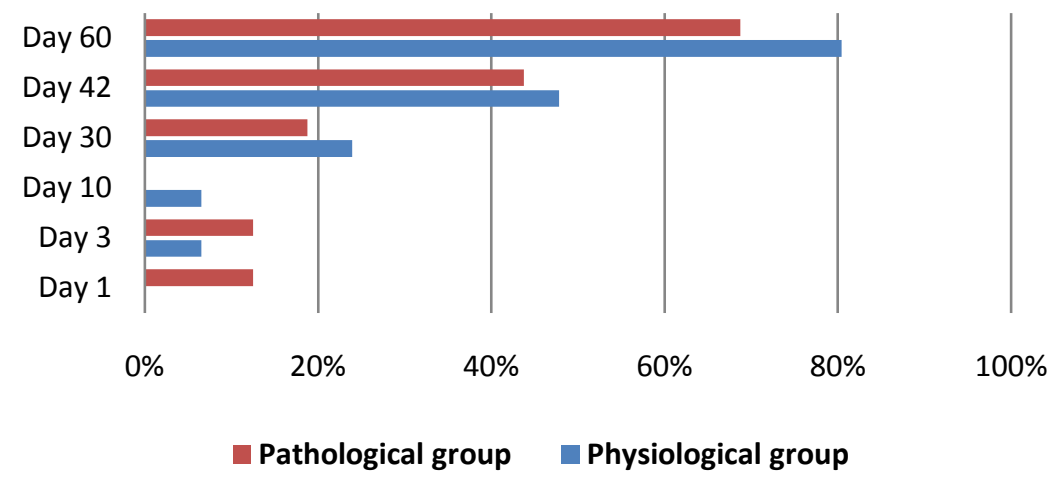

Figure 8. Notching of the uterine artery $(\mathrm{p}>0.05)$.

appearance of the diastolic notch occurs not in all women even after two postpartum months.

Nine women were monitored for the changes in the uterine scar. No one of these operated women suffered from a fever or bleeding. The length (thickness), 
the width and the localisation of the scar depend on the size, the deflection and the involution period of the uterus. The scar thickness varies over a period of up to 8 postpartum weeks. The length and width of the scar in longitudinal plane were $27 \times 6 \mathrm{~mm}$ within two hours after $\mathrm{c} / \mathrm{s}$ and $15 \times 4 \mathrm{~mm}$ after 8 postpartum weeks respectively. The early scar view changes from more hyperechoic to more hypoechoic and is becoming to be niche-like, cyst-like or stripe-like at the end of puerperium (Figure 9).

No particular difference was observed in the uterine size parameters of the operated uterus in comparison with the non-operated uterus.

This study revealed no specific view of early endometritis. No statistically significant correlations were found $(p>0.05)$ between the uterine involution parameters and the infant birth weight, anemia, B group streptococcus infection, smoking, meconium stained amniotic fluid, the placental site (anterior or posterior uterine walls) neither in physiological nor in pathological groups.

\section{Discussion}

The study showed no specific difference between the normal uterine size involution and the involution after complicated deliveries. The main reason for such results may be the fact, that we have observed women with early-onset pathological conditions. The same trend observed in such groups of patients was presented by other authors [1] [2] [9] [11] [14] [15] [16]. The AP diameter achieved the same dimension in both groups already on day 42 , but a sharper decrease was recorded during the first month after normal labour. Our measurements of AP are slightly lower on the first day after labour in both groups (the physiological

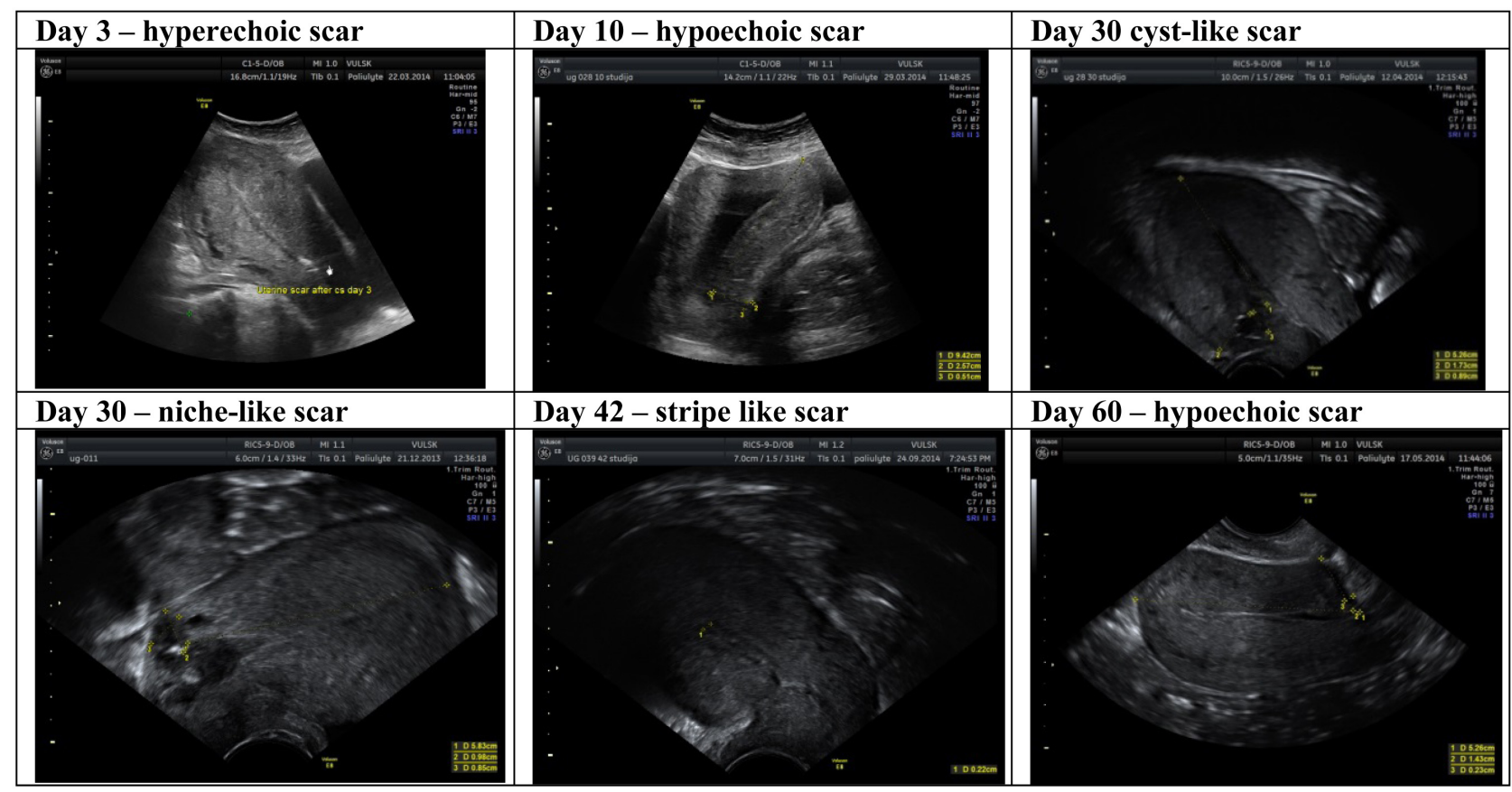

Figure 9. Uterine scar view changes. 
group $-89.5 \mathrm{~mm}$; the pathological group $-82.0 \mathrm{~mm}$ ) compared to the data obtained by other authors [14] (the physiological group- $92.0 \mathrm{~mm}$; the pathological group-90.2 $\mathrm{mm}$ ), however, the differences may have occurred due to the differences in the measurement time. All our patients were scanned for the first time within two hours after labour or $\mathrm{C} / \mathrm{S}$, when the uterus was well-contracted and with smaller parameters.

The fluid or mixed echogenicity is not common either after normal labour, or in the pathological group. The hyperechoic cavity is much more commonly seen in the early puerperium (1,3 days) and at the end of this period (42, 60 days) in the physiological group. Fluid insertion prevails from the $10^{\text {th }}$ day in both groups, however, it is wider and longer seen in the pathological group. A wider cavity after complicated labour on 7, 14 postpartum days is described by other authors [1] [9] [14].

Gas appearance (multiple hyperechogenic foci within the endometrium with a posterior shadow) [25] [26], as claimed by other authors, could range from 5\% after a normal delivery [1] [14] to $16 \%-21 \%$ after a complicated delivery [14] [25] [26] and sometimes remains till the end of puerperium. This study detected gas presentation in $10 \%$ and $39 \%$ normal and complicated delivery cases respectively. Even though our study, if compared to other studies [14] [25] [26], shows a faster disappearance of gas presentation, the risk factor of gas appearance is the same, i.e. operative uterine manipulations ( $\mathrm{C} / \mathrm{S}$ or operative evacuation of RTP). The previous studies show that gas was considered to be a specific sign of postpartum endometritis [8] [26], whereas subsequent studies (including this study) have shown that gas may be a normal finding during the puerperium and does not necessarily indicate the presence of endometritis or RPT [1] [14].

The most different angle is detected only on the first day postpartum. Less common anteverted uterus will be seen after complicated labour. However, the uterus is likely to be more anteverted on the first day (59.90 \pm 17.11 degree) in the group after the operative RPT evacuation than in the remaining part of patients belonging to the pathological group, while the uterine angle is similar to that observed in the physiological group (61.50 \pm 14.36 degree). Other authors found the same correlation on the first postpartum day [14].

Lack of scholarly data on the correlation of the uterine artery indices (RI, PI) after normal and complicated deliveries prevents us from a more detailed discussion of our data. Taking into account that our study showed no significant difference between the physiological and pathological groups, a more useful alternative could be made to apply Doppler ultrasound not for involution monitoring but for detecting RPT. Although RPT is associated with lower resistance indices in the uterine arteries, this knowledge has a limited value as a diagnostic tool for RPT. The absence of a hyper-vascular area in the myometrium does not exclude RPT, but its presence is a common finding associated with RPT and should not be misinterpreted as an arterio-vascular malformation [9]. Even though notching of the uterine artery is one of the indices of the uterine involution changes [1] [6] [9] [14], an absent diastolic notch cannot be a negative in- 
dicator of involution either after normal labour, or complicated labour due to the fact that a diastolic notch does not appear in all women even after two months following labour.

Scholars are still looking for the indicators defining the view of the completeness of the uterine incision healing [19] [20] [21]. Are the fluid inserts at the scar location likely to be the signs of incomplete healing? The hypoechoic view in our cesarean delivery group tended to be more frequent from the beginning till the end of involution. Thus, the hypoechoic stripe within the scar does not mean any myometrial uncontinuity. The largest changes of the scar occur within the first month after $\mathrm{C} / \mathrm{S}$. It is difficult to compare the data as other authors deal with the monitoring interval ranging from week 1 to 6 after C/S or later [19] [20] [21]. We have measured the length and the width of the scar from the early puerperium, because the niche view (recorded by other authors) in our study starts to be determined just from $30^{\text {th }}$ or $42^{\text {nd }}$ postpartum days. Other authors recommend measuring the depth of the niche and the thickness of the remaining myometrium [15] [20] [27]-[37]. For better imaging of the scar, the niche sonohysterography is recommended [30] [38]. We have found that the length and the width of the scar still change from the $6^{\text {th }}$ till the $8^{\text {th }}$ postpartum weeks due to the fact that the complete healing of the scar occurs about 6 months after C/S [39]. It is already known that late differences of the $\mathrm{C} / \mathrm{S}$ scar remain depending on the number of $\mathrm{C} / \mathrm{S}$, the type of $\mathrm{C} / \mathrm{S}$ (elective or urgent), the duration of labour before C/S [19] [34], postpartum anaemia, antibiotics administration [35]. The uterine scar imaging sometimes needs auxiliary methods, e.g. magnetic resonance [39].

Of course, there are some limitations of this study: too small number of women with labor complications, a lack of patients with uterine scar. The present findings of this study are only observational and too narrow to draw more comprehensive conclusions. We are planning to continue our initiated research in the future with group of patients after complicated labor.

\section{Summary}

Neither a delivery method (vaginal or caesarean) nor even the manipulation inside the uterine cavity soon after labour impacts the main parameters of the uterine size or the uterine artery indices during the involution process. Gas appearance is more commonly visible after complicated than normal deliveries which is not only a specific sign of postpartum endometritis. The uterine artery indices should not be included for uterine involution observation after complicated labour. The uterine scar after caesarean delivery needs more specific parameters for observation. Early observation of uterine scar did not provide useful information about scar healing. The scar would be better visualised and evaluated if several screening methods (ultrasound, magnetic resonance) were employed.

\section{Acknowledgements}

I express my gratitude to all the patients who participated in this study despite 
their condition after giving birth and the newborn at home. I am thankful to my research supervisor Prof. Grazina Stanislava Drasutiene, the most important person in the clinic who continuously encourages doctors to go ahead. I extend my sincere gratitude to a team of consultants: Prof. Diana Ramasauskaite, Assoc. Prof. Daiva Bartkeviciene, Assoc. Prof. Jolita Zakareviciene for their valuable insight and input. Special thanks to Grazina Binkauskiene, biostatistics specialist for help in conducting the statistical analysis of the data. My deepest appreciation goes to Professor Juozas Kurmanavicius for consulting me in ultrasound methodology and manuscript writing.

\section{Conflicts of Interest}

The authors declare no conflicts of interest regarding the publication of this paper.

\section{References}

[1] Mulic-Lutvica, A. (2012) Postpartum Ultrasound, Review Article. Donald School Journal of Ultrasound in Obstetrics and Gynecology, 6, 76-92.

[2] Sokol, E.R., Casele, H. and Haney, E.I. (2004) Ultrasound Examination of the Postpartum Uterus: What Is Normal? Journal of Maternal-Fetal \& Neonatal Medicine, 15, 95-99.

[3] Deans, R. and Dietz, H.P. (2006) Ultrasound of the Post-Partum Uterus. Australian and New Zealand Journal of Obstetrics and Gynaecology, 46, 345-349.

[4] Al-Bdour, A.N., Akasheh, H.F. and Al-Husban, N.A. (2004) Ultrasonography of the Uterus after Normal Vaginal Delivery. Saudi Medical Journal, 25, 41-44.

[5] Edwards, A. and Ellwood, D.A. (2000) Ultrasonographic Evaluation of the Postpartum Uterus. Ultrasound in Obstetrics \& Gynecology, 16, 640-643.

[6] Guedes-Martins, L., Gaio, A.R., Saraiva, J., Cunha, A., Macedo, F. and Almeida, H. (2015) Uterine Artery Impedance during the First Eight Postpartum Weeks. Redox Biology, 5, 114-123.

[7] Wataganara, T., Phithakwatchara, N., Komoltri, C., Tantisirin, P., Pooliam, J. and Titapant, V. (2015) Functional Three-Dimensional Sonographic Study of the Postpartum Uterus. Journal of Maternal-Fetal \& Neonatal Medicine, 28, 2221-2227.

[8] Madrazo, B.L. (1985) Postpartum Sonography. The Principle and Practice of Ultrasonography in Obstetrics and Gynecology. 3rd Edition, Appleton-Century-Crofts, East Norwalk, 449-456.

[9] Mulic-Lutvica, A. (2009) Uterine Artery Doppler Ultrasound in Postpartum Women with Retained Placental Tissue. Acta Obstetricia et Gynecologica Scandinavica, 88, 724-728.

[10] Fukuda, M., Fukuda, K., Shimizu, T. and Bujold, E. (2016) Ultrasound Assessment of Lower Uterine Segment Thickness during Pregnancy, Labour, and the Postpartum Period. Journal of Obstetrics and Gynaecology Canada, 38, 134-140.

[11] Van Schoubroeck, D., Van den Bosch, T., Scharpe, K., Lu, C., Van Huffel, S. and Timmerman, D. (2004) Prospective Evaluation of Blood Flow in the Myometrium and Uterine Arteries in Puerperium. Ultrasound in Obstetrics \& Gynecology, 23, 378-381.

[12] Reles, A., Ertan, A.K., Kainer, F. and Dudenhausen, J.W. (1992) Doppler Ultra- 
sound Images of the Uterine Artery and Uterine Involution in Normal Puerperium. Gynakologisch-geburtshilfliche Rundschau, 32, 66-72.

[13] Sohn, C., Fendel, H. and Kesternich, P. (1988) Involution-Induced Changes in Arterial Uterine Blood Flow. Zeitschrift Fur Geburtshilfe Und Perinatologie, 192, 203-209.

[14] Mulic-Lutvica, A. and Axelsson, O. (2007) Postpartum Ultrasound in Women with Postpartum Endometritis, after Cesarean Section and after Manual Evacuation of the Placenta. Acta Obstetricia et Gynecologica Scandinavica, 86, 210-217.

[15] Negishi, H., Kishida, T., Yamada, H., Hirayama, E., Mikuni, M. and Fujimoto, S. (1999) Changes in Uterine Size after Vaginal Delivery and Cesarean Section Determined by Vaginal Sonography in the Puerperium. Archives of Gynecology and $O b-$ stetrics, 263, 13-16.

[16] Rufener, S.L., Adusumilli, S., Weadock, W.J. and Caoili, E. (2008) Sonography of Uterine Abnormalities in Postpartum and Postabortion Patients. A Potential Pitfall of Interpretation. Journal of Ultrasound in Medicine, 27, 343-348. https://doi.org/10.7863/jum.2008.27.3.343

[17] Cunningham, F.G., Leveno, K.J., Bloom, S.L., Spong, C.Y., Dashe, J.S., Hoffman, B.L., Casey, B.M. and Sheffield, J.S. (2014) Williams Obstetrics. 24th Edition, McGraw-Hill, New York, Chapter 37, 668-671.

[18] Royal College of Obstetricians and Gynaecologists (2012) Bacterial Sepsis Following Pregnancy. Green-Top Guideline No. 64b.

[19] Yazicioglu, F., Gokdogan, A., Kelekci, S., Aygun, M. and Savan, K. (2006) Incomplete Healing of the Uterine Incision after Caesarean Section. Is It Preventable? European Journal of Obstetrics \& Gynecology and Reproductive Biology, 124, 32-36. https://doi.org/10.1016/j.ejogrb.2005.03.023

[20] Dosedla, E., Calda, P. and Kvasnička, T. (2012) Ultrasonography of the Uterus within 6 Weeks Following Cesarean Section. Central European Journal of Medicine, 7, 235-240.

[21] Paliulyte, V., Drąsutienè, G.S., Ramašauskaitė, D., Bartkevičienė, D., Zakarevičienè, J. and Kurmanavičius, J. (2017) Physiological Uterine Involution in Primiparous and Multiparous Women: Ultrasound Study. Obstetrics and Gynecology International, 2017, Article ID: 6739345.

[22] Wachsberg, R.H., Kurtz, A.B., Levine, C.D., Solomon, P. and Wapner, R.J. (1994) Real-Time Ultrasonographic Analysis of the Normal Postpartum Uterus: Technique, Variability, and Measurements. Journal of Ultrasound in Medicine, 13, 215-221. https://doi.org/10.7863/jum.1994.13.3.215

[23] Swiss Society for Ultrasound in Medicine, Sektion Gynäkologie und Geburtshilfe (SGUMGG), Gynaecology and Obstetrics Section. Swiss Gynaecologic Ultrasound Guideline, 2nd Version, Schweizerische Gesellschaft für Ultraschall in der Medizin. http://www.geburtshilfe.usz.ch/fachwissen/Documents/ultraschall-empf-eng.pdf

[24] American Institute of Ultrasound in Medicine (2014) AIUM Practice Parameter for the Performance of Ultrasound of the Female Pelvis.

http://www.aium.org/resources/guidelines/femalepelvis.pdf

[25] Wachsberg, R.H. and Kurtz, A.B. (1992) Gas within the Endometrial Cavity at Postpartum US: A Normal Finding after Spontaneous Vaginal Delivery. Radiology, 183, 431-433. https://doi.org/10.1148/radiology.183.2.1561345

[26] Piek, P.C., Fuchs, N., Venter, P.F., van der Merwe, C.A. and Koch, Z. (1989) The Ultrasonic Demonstration of Gas in the Endometrial Cavity-An Aid for the Diagnosis of Puerperal Endometritis. South African Medical Journal, 76, 203-205. 
[27] Poidevin, L.O. (1961) The Value of Hysterography in the Prediction of Cesarean Section Wound Defects. American Journal of Obstetrics \& Gynecology, 81, 67-71. https://doi.org/10.1016/S0002-9378(16)36308-6

[28] Burger, N.F., Darazs, B. and Boes, E.G. (1982) Anechographice Valuation during the Early Puerperium of the Uterine Wound after Caesarean Section. Journal of Clinical Ultrasound, 10, 271-274. https://doi.org/10.1002/jcu.1870100605

[29] Chen, H.Y., Chen, S.J. and Hsieh, F.J. (1990) Observation of Cesarean Sections Carbytransvaginal Ultrasonography. Ultrasound in Medicine \& Biology, 16, 443-447. https://doi.org/10.1016/0301-5629(90)90166-A

[30] Naji, O., Abdallah, Y., Bij De Vaate, A.J., Smith, A., Pexsters, A., Stalder, C., McIndoe, A., Ghaem-Maghami, S., Lees, C., Brölmann, H.A.M., Huirne, J.A.F., Timmerman, D. and Bourne, T. (2012) Standardized Approach for Imaging and Measuring Cesareansections Carsusing Ultrasonography. Ultrasound in Obstetrics and Gynecology, 39, 252-259.

[31] Osser, O.V. and Valentin, L. (2010) Riskfactors for Incomplete Healing of the Uterine Incision after Caesarean Section. BJOG, 117, 1119-1126. https://doi.org/10.1111/j.1471-0528.2010.02631.x

[32] Osser, O.V., Jokubkiene, L. and Valentin, L. (2009) High Prevalence of Defects in Cesarean Sectionscars at Transvaginal Ultrasound Examination. Ultrasound in $\mathrm{Ob}$ stetrics \& Gynecology, 34, 90-97. https://doi.org/10.1002/uog.6395

[33] Osser, O.V., Jokubkiene, L. and Valentin, L. (2008) Longduration of Laborand Post-Partumanemia Increase the Risk of Large Defects in Caesarean Sectionscars. Ultrasound in Obstetrics \& Gynecology, 32, 389. https://doi.org/10.1002/uog.5868

[34] Bij de Vaate, A.J.M., Brölmann, H.A.M., Van der Voet, L.F., Van der Slikke, J.W., Veersema, S. and Huirne, J.A.F. (2011) Ultrasoun Devaluation of the Cesareanscar: Relation between a Niche and Postmenstrual Spotting. Ultrasound in Obstetrics and Gynecology, 37, 93-99.

[35] Van derVoet, L.F., Jordans, I.P.M., Brölmann, H.A.M., Veersema, S. and Huirne, J.A.F. (2017) Changes in the Uterine Scar during the First Year after a Caesarean Section: A Prospective Longitudinal Study. Gynecologic and Obstetric Investigation, 83. https://doi.org/10.1159/000478046

[36] Van derVoet, L.F., Bij de Vaate, A.M., Veersema, S., Brölmann, H.A. and Huirne, J.A. (2014) Long-Term Complications of Caesarean Section. The Niche in the Scar: A Prospective Cohort Study on Niche Prevalence and Its Relation to Abnormal Uterine Bleeding. BJOG, 121, 236-244.

[37] Monteagudo, A., Carreno, C. and Timor-Tritsch, I.E. (2001) Saline Infusion Sonohysterography in Nonpregnant Women with Previuos Cesarean Delivery: The Niche Inthescar. Journal of Ultrasound in Medicine, 20, 1105-1115.

https://doi.org/10.7863/jum.2001.20.10.1105

[38] Ofili-Yebovi, D., Ben-Nagi, J., Sawayer, E., Yazbek, J., Lee, C., Gonzalez, J. and Jurkovic, D. (2008) Deficientlower-Segment Cesarean Sectionscars: Prevalence and Risk Factors. Ultrasound in Obstetrics \& Gynecology, 31, 72-77. https://doi.org/10.1002/uog.5200

[39] Dicle, O., Küçükler, C., Pirnar, T., Erata, Y. and Posaci, C. (1997) Magnetic Resonance Imaging Evaluation of Incision Healing after Cesarean Sections. European Radiology, 7, 31-34. https://doi.org/10.1007/s003300050103 


\section{Abbreviations}

RPT-retained placental tissues.

$\mathrm{C} / \mathrm{S}$-caesarean section.

$\mathrm{RI}-$ resistance index.

PI-pulsatility index. 